\title{
Design and Development of a Multicultural Competence Scale in Helping-Profession Students
}

\author{
Jakub Hladik ${ }^{1}$ \\ ${ }^{1}$ Faculty of Humanities, Tomas Bata University in Zlín, Czech Republic \\ Correspondence: Jakub Hladik, Faculty of Humanities, Tomas Bata University in Zlín, nám. T. G. Masaryka \\ 5555, 76001 Zlín, Czech Republic. Tel: 420-7-2443-4560. E-mail: hladik@fhs.utb.cz
}

Received: January 21, 2014

Accepted: March 14, 2014 Online Published: April 29, 2014

doi:10.5539/ass.v10n9p162

URL: http://dx.doi.org/10.5539/ass.v10n9p162

\begin{abstract}
The study focuses on designing a Multicultural Competence Scale in Helping-Profession Students. The aim was to create an assessment tool of multicultural competence in students of helping professions as such a tool has been non-existent so far in the Central Europe. The scale construction was inspired by the four following instruments: CBMCS, MAKSS, MSPCCS and IIMCS. Through content validation, exploratory factor analysis and confirmatory factor analysis, the original 58 scales were reduced to a 20-item final version of the MCSHPS, which includes scales of the following five factors: Knowledge, Understanding of terms, Activity, Awareness and Communication skills.
\end{abstract}

Keywords: multiculrual competence, helping profession, factor analysis, scale development

\section{Introduction}

Helping professions are those aimed at helping clients in difficult life situations (e.g. social work), aimed at human development in the physical area (e.g. healthcare degree courses) and in the mental area (e.g. psychology), and the development of cognitive aspects of a personality (e.g. pedagogical degree courses). Undergraduate students of helping professions are to be prepared for work and interaction with cultural and ethnic minorities in the course of their studies. In the Czech Republic, where the research was done, students of helping professions are almost exclusively members of the population majority. Due to the fact that such multicultural preparation has not been standardised, it differs in teaching methods, content, and even in goals. Educators in the field of multicultural education are in urgent need of a tool that would allow detection of the level of multicultural competence in students at the beginning, during and at the end of the training process. We have therefore decided to develop a tool that would enable an assessment of multicultural competence in students. The aim of this study is to describe the development of Multicultural Competence Scale in Helping-Profession Students (MCSHPS).

The need for a culturally sensitive approach in psychological counselling has been a matter of discussion since 1970s (Gamst, Linag \& Der-Karabetian, 2011). The term multicultural competence enters the field in the early 1980s. Sue, Bernier, Durran, Feinberg, Pedersen, Smith \& Vazquez-Nutall (1982) described three components of multicultural competence: awareness, knowledge and skill. This ternary (three-dimensional) model was used to improve the quality of provision of psychological counselling in multicultural settings. There are many definitions of multicultural competence (e.g., Sue, Bernier, Durran, Feinberg, Pedersen, Smith \& Vazquez-Nutall, 1982; Pope \& Reynolds, 1997; Byram, 1997; Sue, Carter, Casas, Fouad, Ivey, Jensen, LaFromboise, ... Vazquez-Nutall, 1998; Deardorff, 2006, 2009). For the purpose of this paper we use the definition of D. K. Deardorff (2006) that a multicultural competence is "the ability to communicate effectively and appropriately in intercultural situations. Such ability is based on intercultural knowledge, skills and attitudes."

Multicultural competence is understood in a holistic concept as a global (holistic, comprehensive) "ability ". It is a set of knowledge, skills, attitudes and actions allowing the individual to communicate effectively in a multicultural environment. Multicultural competence is usually broken down into its components, and is conceptualized in the model of multicultural competence. There are various conceptions of multicultural competence models which differ mainly in the components of which the models consist (see Gamst, Linag \& Der-Karabetian, 2011). Deardorff (2006) describes the Pyramid model of intercultural competence consisting of the attitude, knowledge, skills and behavioural components (the behavioural component being at the top of the pyramid). Fantini (2000) identifies the following components in his Intercultural communicative competence 
model (ICC): attitudes, knowledge, skills and awareness. Byram (1997), Sue, Carter, Casas, Fouad, Ivey, Jensen, LaFromboise, ...Vazquez-Nutall (1998), Byram, Nichols and Stevens (2001) consistently rank knowledge, skills and attitudes in the complex of multicultural competence. Pope, Reynolds, and Mueller (2004) operate with these components: multicultural awareness, knowledge and skills. Lustig and Koester (2010) work with the components of knowledge, motivation and a behavioural component. The relations among the components of multicultural competence models were also a matter of various studies (e.g. Pope \& Mueller, 2000; Gamst, Dana, Der-Karabetian, Aragon, Arellano, Morrow \& Martenson, L., 2004; Castelanos, Gloria, Mayorga, \& Salas, 2007; Hladik, 2011). We consider multicultural competence to be a significant part of the professional competence of students in helping professions. It is the workers in helping professions who are in a frequent contact with culturally different clients. An effective and appropriate method of communication is thus necessary in such situations.

Four existing tools of assessment of multicultural competence were used when designing MCSHPS: The California Brief Multicultural Competence Scale (CBMCS) (Gamst, Dana, Der-Karabetian, Aragon, Arellano, Morrow \& Martenson, 2004); The Multicultural Awareness, Knowledge, and Skills Survey (MAKSS) (Kim, Cartwright, Asay \& D'Andrea, 2003); Multicultural School Psychology Counseling Competency Scale (MSPCCS) (Rogers \& Ponterotto, 1997) and Individual Importance of Multicultural Competence Scale (IIMCS) (Hladik, Hrbackova \& Vavrova, 2012). We also analysed other tools, e.g. Multicultural Counseling Knowledge and Awareness Scale (MCKAS) (Ponterotto, Gretchen, Utsey, Rieger \& Austin, 2002) or Multicultural Counseling Inventory (MCI) (Sodowsky, Taffe, Gutkin, \& Wise, 1994), however the items of these scales were not used when constructing MCSHPS.

The CBMCS is a multidimensional self-report instrument designed in 2004 that purports to measure the cultural competencies of mental health practitioners. CBMCS contains 21 items. The answers are recorded on a Likert-type scale: $4=$ strongly disagree, $3=$ disagree, $2=$ agree, $1=$ strongly agree. This tool comprises of four factors: 1) Socio-cultural diversities, 2) Awareness of cultural barriers, 3) Multicultural knowledge, 4) Sensitivity to consumers (Gamst, Dana, Der-Karabetian, Aragon, Arellano, Morrow \& Martenson, 2004).

MAKSS is a tool to measure multicultural competence based on a three-dimensional concept (see Sue, Bernier, Durran, Feinberg, Pedersen, Smith \& Vazquez-Nutall, 1982; Pope \& Reynolds, 1997; Pope, Reynolds \& Mueller, 2004). MAKSS is composed of 33 items belonging to three components: knowledge, awareness and skills with responses recorded on a Likert-type scale, based on their nature, using the following bipolar points: 1 = very limited, $4=$ very aware; $1=$ very limited, $4=$ very good; $1=$ strongly disagree, $4=$ strongly agree $($ Kim, Cartwright, Asay \& D'Andrea, 2003).

The MSPCCS is a uni-dimensional instrument which assesses the trainer's perceptions of the multicultural school psychology counselling competencies of graduating trainees. MSCPCCS consists of 11 items. The responses are recorded on a Likert-type scale: $1=$ not at all, $4=$ very much (Rogers \& Ponterotto, 1997).

IIMCS was created to assess the importance of various multicultural subcompetencies of students in helping professions. IIMCS contains 30 items divided, as in MAKSS, into three dimensions: 1) Multicultural knowledge, 2) Multicultural awareness, 3) Multicultural skills. The responses were recorded using a seven-point Likert-type scale (Hladik, Hrbackova \& Vavrova, 2012).

The first three tools/instruments were selected as they represent already established approaches to assess multicultural competence. Unlike the previous tools, the final scale (IIMCS) comes directly from a cultural environment in which MCSHPS tool presented in this study was also developed. It should be noted that the content of multicultural competence is culturally bound, i.e. it is dependent on the culture in which it is acquired. Therefore in order to achieve a more accurate measurement of multicultural competence, the cultural context of the given location (country, region) should be taken into account. In other words, it proved beneficial to use certain items from a scale used previously in the given cultural context (Czech Republic, Central Europe) when developing MCSHPS.

\section{Scale Development}

The Method section describes in detail how the study was conducted, including conceptual and operational definitions of the variables used in the study, Different types of studies will rely on different methodologies; however, a complete description of the methods used enables the reader to evaluate the appropriateness of your methods and the reliability and the validity of your results, It also permits experienced investigators to replicate the study, If your manuscript is an update of an ongoing or earlier study and the method has been published in detail elsewhere, you may refer the reader to that source and simply give a brief synopsis of the method in this section. 
First, we worked with items of the following scales: CBMCS, MAKSS and MSPCCS. The scale was designed for distribution among Czech students. With regard to maximum clarity of the constructed scale, the items were translated into the Czech language. From each scale, items were selected in order to suit the use in university students, with special regard to their little practical experience concerning performance of a helping profession. In many cases the selected items had to be reformulated so that they were most comprehensible to the students (due to little work experience or cultural context). For example item 9 in CBMCS - "My communication skills are appropriate for my clients" was reworded to "I can communicate adequately with members of minorities." Furthermore, items from IIMCS that most correlate with helping professions were selected. Also, based on literature and our own experience with providing multicultural education to students, several items were added to the basic item pool. Finally a 58 -item pool was created.

Two experts from Tomas Bata University in Zlín on the issues of multicultural education and multicultural competence ensured content validity by rating independently all 58 items of MCSHPS regarding suitability of item classification on a three-point scale: 1 = absolutely agree, $3=$ absolutely disagree. Based on the content validation 7 items were removed due to the lowest average score recorded by the evaluators $(\mathrm{M}=2.5) ; 1$ item removed after a discussion with the evaluators due to its difficulty and 1 item was removed as a duplicate. After the reduction, MCSHPS contained 49 items.

\section{Method}

The participants were undergraduate students of the Faculty of Humanities, Tomas Bata University in Zlín ( $\mathrm{n}=$ $363)$. $N=361$ aged under 26 and $n=2$ over 26 years of age. Women $n=338(93 \%)$ and males $n=25(7 \%)$. More precisely, they were students of pedagogical, healthcare and social fields who are being prepared for helping professions. The participants completed a 49-item MCSHPS using the paper and pencil method. Responses were recorded on a 5-point Likert-type scale: $1=$ absolutely disagree, $5=$ absolutely agree. The 49-item version of MCSHPS consisted of modified items from CBMCS $(\mathrm{n}=9)$, MAKSS $(\mathrm{n}=10)$, MSPCCS ( $=3)$, IIMCS $(\mathrm{n}=15)$ and new items $(\mathrm{n}=12)$.

\section{Results}

\subsection{Exploratory Factor Analysis}

We were interested in the factor structure of the 49-item version of MCSHPS. The proposed factor solution was further subjected to a confirmatory factor analysis (CFA). The SPSS version 21 was used for exploratory factor analysis and SPSS AMOS version 21 was used for CFA.

To determine the construct validity of MCSHPS, exploratory factor analysis was used. Corrected item total correlation showed a value of less than .20 in three items (3, 7 and 41). These items were thus not included in the exploratory factor analysis. No extreme variance was recorded in any of the items, therefore, the factor analysis of the 46-item version of MCSHPS was carried out. Based on the scree test analysis, a 5-factor structure of MCSHPS was chosen, see Table 1. An analysis of the principal components, i.e. orthogonal factor rotation was done, using the Varinmax norm. method. We concentrated on items with factor loading greater than or equal to .55 .

We have generated five factors with a total common variance $=45.63 \%$ and with Cronbach coefficient $\alpha=.92$. The value of total common variance as well as estimate reliability was considered very good.

Table1. Factor structure of 46-item MCSHPS

\begin{tabular}{|c|c|c|c|c|c|c|c|c|}
\hline \multirow[b]{2}{*}{ Item } & \multicolumn{5}{|c|}{ Factor } & \multirow[b]{2}{*}{$\mathrm{h}^{2}$} & \multirow[b]{2}{*}{$\mathrm{M}$} & \multirow[b]{2}{*}{ SD } \\
\hline & 1 & 2 & 3 & 4 & 5 & & & \\
\hline I_1 & .11 & -.19 & .05 & .45 & .06 & .38 & 3.69 & 0.91 \\
\hline I_2 & -.07 & .05 & -.15 & .36 & .11 & .34 & 4.10 & 0.91 \\
\hline I_4 & .05 & .06 & .02 & -.02 & -.13 & .37 & 3.60 & 0.95 \\
\hline I_5 & .01 & .30 & -.06 & .02 & .27 & .36 & 3.99 & 0.86 \\
\hline I_6 & .09 & .16 & .00 & .31 & .15 & .47 & 4.16 & 0.85 \\
\hline I_8 & -.08 & .11 & .17 & -.08 & -.11 & .38 & 3.64 & 1.02 \\
\hline I_9 & .04 & .09 & .24 & -.09 & .17 & .27 & 3.86 & 1.04 \\
\hline
\end{tabular}




\begin{tabular}{|c|c|c|c|c|c|c|c|c|}
\hline I_10 & .23 & .19 & .25 & .36 & .19 & .43 & 3.80 & 0.86 \\
\hline I_11 & .24 & .28 & .14 & $\underline{.55}$ & .00 & .48 & 3.73 & 1.04 \\
\hline I_12 & -.04 & .28 & .11 & $\underline{.58}$ & .03 & .48 & 4.19 & 0.86 \\
\hline I_13 & .16 & .23 & -.01 & .13 & -.07 & .40 & 3.75 & 0.92 \\
\hline I_14 & .06 & .11 & .18 & .19 &. .67 & .54 & 3.56 & 0.92 \\
\hline I_15 & .18 & .29 & .01 & .15 & .19 & .30 & 3.64 & 0.85 \\
\hline I_16 & .23 & .31 & .22 & .02 & .31 & .38 & 3.84 & 0.99 \\
\hline I_17 & .13 & .27 & -.03 & .18 & .45 & .33 & 3.68 & 0.87 \\
\hline I_18 & .20 & .32 & .05 & .09 & .44 & .41 & 3.76 & 0.91 \\
\hline I_19 & .09 & .15 & .01 & .45 & .54 & .53 & 3.55 & 0.94 \\
\hline I_20 & -.13 & .09 & .17 & $\underline{.62}$ & .44 & .59 & 4.08 & 0.91 \\
\hline I_21 & .16 & .07 & .32 & -.18 & $\underline{.69}$ & .62 & 3.11 & 0.97 \\
\hline I_22 & .14 & .05 & .18 & .11 & $\underline{.68}$ & .53 & 3.33 & 0.94 \\
\hline I_23 & .18 & .14 & .22 & .38 & .43 & .42 & 3.51 & 0.82 \\
\hline I_24 & .51 & .11 & .05 & .02 & .32 & .47 & 2.90 & 1.00 \\
\hline I_25 & .53 & -.07 & .09 & .04 & .37 & .43 & 2.83 & 0.97 \\
\hline I_26 & .24 & .18 & .15 & .53 & -.03 & .38 & 3.52 & 1.01 \\
\hline I_27 & .77 & .07 & .03 & .06 & .05 & .61 & 2.63 & 1.08 \\
\hline I_28 &. & .05 & .08 & .06 & -.06 & .48 & 2.31 & 1.05 \\
\hline I_29 &. .64 & .10 & .43 & .15 & .01 & .58 & 2.58 & 1.04 \\
\hline I_30 & $\underline{.62}$ & .11 & .27 & .09 & .13 & .50 & 2.94 & 0.97 \\
\hline I_31 & $\underline{.58}$ & .18 & .23 & .07 & .12 & .48 & 3.18 & 1.04 \\
\hline I_32 & $\underline{.56}$ & .22 & .27 & .07 & .06 & .50 & 2.93 & 1.06 \\
\hline I_33 & .16 & .75 & .14 & .05 & .09 & .64 & 3.92 & 0.88 \\
\hline I_34 & .34 & $\underline{.59}$ & .06 & .09 & .11 & .50 & 3.52 & 1.03 \\
\hline I_35 & -.02 & $\underline{.80}$ & .07 & .07 & .06 & .67 & 4.36 & 0.77 \\
\hline I_36 & -.02 & .81 & .06 & .16 & .06 & .70 & 4.27 & 0.87 \\
\hline I_37 & .04 & .77 & .08 & .15 & .12 & .65 & 4.03 & 0.98 \\
\hline I_38 & .34 & .51 & .03 & .16 & .15 & .46 & 3.41 & 1.17 \\
\hline I_39 & .17 & .44 & .21 & .28 & .12 & .44 & 3.89 & 0.91 \\
\hline I_40 & -.08 & .11 & .24 & $\underline{.65}$ & .39 & .61 & 4.07 & 0.97 \\
\hline I_42 & .16 & .06 & .36 & .35 & .29 & .33 & 3.25 & 0.95 \\
\hline I_43 & .30 & .01 & .49 & .26 & .15 & .43 & 2.80 & 1.13 \\
\hline I_44 & .06 & .11 & .72 & .32 & .04 & .64 & 3.41 & 1.09 \\
\hline I_45 & .23 & .10 &. .77 & .08 & .20 & .71 & 3.04 & 1.01 \\
\hline I_46 & .12 & .05 & $\underline{.63}$ & .34 & .24 & .58 & 3.39 & 0.92 \\
\hline I_47 & .48 & .15 & .51 & -.02 & .10 & .58 & 3.01 & 0.99 \\
\hline I_48 & .29 & .06 & $\underline{.65}$ & .02 & .12 & .53 & 2.76 & 1.06 \\
\hline I_49 & .48 & .13 & .41 & -.10 & .25 & .51 & 2.99 & 0.96 \\
\hline Eigenvalue & 10.94 & 3.67 & 2.78 & 1.82 & 1.68 & & & \\
\hline$\%$ of variance & 23.78 & 7.99 & 6.05 & 3.97 & 3.84 & & & \\
\hline Coefficient $\alpha$ & .82 & .85 & .81 & .68 & .72 & & & \\
\hline
\end{tabular}


1. The Knowledge factor ( $\mathrm{n}=6$ items). Factor loadings vary in the range from .56 to .77 . The factor explains $23.78 \%$ (eigenvalue $=10.94$ ) of the total common variance. Coefficient $\alpha=.82 .2$. The Understanding of terms factor $(\mathrm{n}=5$ items). Factor loadings range from .59 to .81 . The factor explains $7.99 \%$ of the total common variance (eigenvalue $=3.67$ ). Coefficient $\alpha=.85 .3$. The Activity factor $(\mathrm{n}=4$ items). Factor loadings were observed in the range from .63 to .77 . The value of variance is $6.05 \%$ (eigenvalue $=2.78$ ) and the coefficient $\alpha$ $=.81$. 4. The Awareness factor ( $\mathrm{n}=4$ items) exhibits factor loadings in the range from .55 to .65 . This factor explains $3.97 \%$ of the total common variance (eigenvalue $=1.82$ ). Coefficient $\alpha=.68$, which is the lowest value of all the factors, but given the number of items $(n=4)$ this is considered to be an acceptable value. 5 . The Communication skills factor $(\mathrm{n}=3$ items). Factor loadings range from .67 to .69 . The value of variance is $3.84 \%$ (eigenvalue $=1.68)$. The reliability estimate is very good $(\alpha=.72)$ due to the low number of items.

By removing 24 items with factor loading below .55, the 46-item vision was reduced to a 22 -item 5 -factor version of MCSHPS.

\subsection{Confirmatory Factor Analysis}

A confirmatory factor analysis (CFA) was conducted in order to test the structure of a 5-factor MCSHPS model. CFA can be used to examine the latent (i.e. the unobserved underlying construct) structure of an instrument during scale development (Harrington, 2009). In the CFA, we investigated the following parameters: chi-square, $\mathrm{p}$ value, root mean square error of approximation (RMSE), goodness of fit index (GFI), adjusted goodness of fit index (AGFI), comparative fit index (CFI), standardized root mean square residual (SPDC). These are standard parameters used for testing via CFA (Harrington, 2009; Albright \& Park, 2009; Brown, 2006; Kaplan, 2004).

Table 2. Confirmatory analysis results

\begin{tabular}{lccccccc}
\hline & $\mathrm{Chi}^{2}$ & $\mathrm{p}$ value & RMSEA & GFI & AGFI & CFI & SRMR \\
\hline $\begin{array}{l}20 \text { items } \\
5 \text { factor model }\end{array}$ & 2.457 & .001 & .063 & .910 & .880 & .918 & .063 \\
MCSHPS & & & & & & & \\
\hline
\end{tabular}

Table 2 shows the results of modelling through CFA. We removed 2 items with high residual value (items 11 and $34)$. The final 20 -item model of MCSHPS was produced. The values of chi-square, $p$ value and RMSE are considered acceptable due to the low number of participants $(n=363)$. We expect that the results of CFA for our sample do not differ from the expected results of the whole population. Other parameters (GFI, AGFI, CFI) indicate good fit of the 20 -item model.

The final MCSHPS model contains 20 items and 5 factors (Tab 3.). 1. The Knowledge factor contains six items with factor loading from .56 to $.77, \alpha=.82$. 2. The Understanding of terms factor contains 4 items with factor loading in the range from .75 to $.81 ; \alpha=.85$. 3. The Activity factor is composed of 4 items with factor loading from .63 to $.77, \alpha=.81$. 4. The Awareness factor contains three items with factor loading ranging from .60 to .65 , $\alpha=.68$. 5. The Communication skills factor consists of 3 items with factor loading in the range from .67 to $.69, \alpha$ $=72$.

Table 3. Factor structure of 20-item MCSHPS

\begin{tabular}{|c|c|c|c|c|c|c|c|c|}
\hline \multirow[b]{2}{*}{ Item } & \multicolumn{5}{|c|}{ Factor* } & \multirow[b]{2}{*}{$h^{2}$} & \multirow[b]{2}{*}{$\mathrm{M}$} & \multirow[b]{2}{*}{ SD } \\
\hline & $\mathrm{K}$ & UoT & $\mathrm{Ac}$ & Aw & $\mathrm{C}$ & & & \\
\hline $\begin{array}{l}\text { 1.I am familiar with the immigrant } \\
\text { integration process in my country. }^{c}\end{array}$ & .77 & & & & & .61 & 2.63 & 1.08 \\
\hline $\begin{array}{l}\text { 2. I know the number of foreigners } \\
\text { in my country and their } \\
\text { nationalities. }\end{array}$ & .68 & & & & & .48 & 2.31 & 1.05 \\
\hline $\begin{array}{l}\text { 3. I am aware of the possibilities of } \\
\text { implementing multicultural } \\
\text { education into practice. }\end{array}$ & .64 & & & & & .58 & 2.58 & 1.04 \\
\hline
\end{tabular}


4. I know the specifics of working with minorities. ${ }^{\mathrm{c}}$

5. I know the cultural specifics of Roma, Vietnamese and Ukrainians living in my country. ${ }^{\mathrm{e}} * *$

6. I understand literature dealing with multicultural issues. ${ }^{\text {a }}$

7. I understand the concept of racism very well. ${ }^{\mathrm{b}}$

8. I understand the concept of prejudice very well. ${ }^{\mathrm{b}}$

9. I understand the concept of egocentrism very well. ${ }^{\mathrm{b}}$

10. I understand the concept of culture very well. b $^{\circ}$

11. I work on my multicultural knowledge, competences and skills. $^{\mathrm{e}}$

12. I am interested in multicultural education. $^{\mathrm{e}}$

13.I think about multicultural education. $^{\mathrm{c}}$

14. I observe and control my behaviour towards members of minorities. ${ }^{\mathrm{e}}$

15. I respect and accept other cultures. $^{\mathrm{d}}$

16. I am aware that cooperation of all parties is necessary in order to achieve a conflict-free cultural contact. $^{\mathrm{c}}$

17. I respect socio-cultural differences. ${ }^{\mathrm{c}}$

18. I can apply various communicative strategies in communication with minority group members. $^{\text {c }}$

19. I am able to contribute to a conflict-free and constructive minority problem solution. ${ }^{\mathrm{c}}$

20. I can communicate adequately with members of minorities. ${ }^{\text {a }}$

\begin{tabular}{llllll}
\hline Coefficient $\alpha$ & .82 & .85 & .81 & .68 & .72
\end{tabular}

Note 1: * Factors: $\mathrm{K}=$ Knowledge; UoT $=$ Understanding of terms; Ac = Activity; Aw = Awareness; $\mathrm{C}=$ Communication skills. ** Roma, Ukrainian and Vietnamese are the most prominent minorities in the Czech Republic, where the research was done. ${ }^{\mathrm{a}}$ Item inspired by CBMCS. ${ }^{\mathrm{b}}$ Item inspired by MAKSS. ${ }^{\mathrm{c}}$ Item from IIMCS. ${ }^{\mathrm{d}}$ Item inspired by MSPCCS. ${ }^{\mathrm{e}}$ Newly created item.

Table 4 lists correlation among factors. The lowest correlation was recorded between the factors of Knowledge and Awareness $(\mathrm{r}=.196)$. The highest correlation was seen between the factors of Knowledge and Activity $(\mathrm{r}$ $=.479$ ). 
Table 4. Correlation among the five factors

\begin{tabular}{llllll}
\hline & 1. & 2. & 3. & 4. & 5. \\
\hline 1. Knowledge & & & & & \\
2. Understanding of terms & $.303^{*}$ & & & & \\
3. Activity & $.479^{*}$ & $.251^{*}$ & & \\
4. Awareness & $.196^{*}$ & $.385^{*}$ & $.429^{*}$ & & \\
5. Communication skills & $.305^{*}$ & $.256^{*}$ & $.384^{*}$ & $.349^{*}$ & \\
\hline
\end{tabular}

Note 2: * Correlation is significant at the .01 level $(2-$ tailed $)$.

\section{Discussion}

The results above describe the development of a scale designed to detect the level of multicultural competence in university students preparing for helping professions. The final solution is a 20 -item scale containing five factors. The Knowledge factor displayed high factor loadings. It is a factor that is often encountered in models of multicultural competence and its measurement (see Sue, Bernier, Durran, Feinberg, Pedersen, Smith \& Vazquez-Nutall, 1982; Pope \& Reynolds, 1997; Ponterotto, Gretchen, Utsey, Rieger \& Austin, 2002; Kim, Cartwright, Asay \& D'Andrea, 2003; Gamst, Dana, Der-Karabetian, Aragon, Arellano, Morrow \& Martenson, L., 2004; Deardorff, 2006). It refers to knowledge of multicultural properties associated with a given region or country, knowledge related to cultural and ethnic minorities, foreigners and migrants. The acquisition of such knowledge occurs within the family, at school and through the media. This factor closely correlates $(\mathrm{r}=.48)$ with the factor of Activity, which serves as a reflection of a personal approach to the multicultural reality. The Activity factor comprises of items that are of a self-regulating character (motivation, planning, control) and is related to multicultural learning. The relationship between the components of self-regulated learning and multicultural knowledge was confirmed and published in our research (Hladik, Hrbackova \& Vavrova, 2012). Understanding of terms is another factor in the proposed 5- factor solution. All four items of this factor were inspired by MAKSS (Kim, Cartwright, Asay \& D'Andrea, 2003). It is a factor with high factor loading due to a low number of items with high reliability $(\alpha=.85)$. This factor was proved to be of an important role when measuring multicultural competence in students of helping professions. These items are closely related with life in a culturally pluralistic society. The Understanding of terms factor closely correlates with the Awareness factor, which is represented by three items in MCSHPS. These items are related to respect and tolerance of different cultural and ethnic groups. The Awareness factor, like the Knowledge factor, is often a part of multicultural competence models and measurement tools (cf. Sue, Bernier, Durran, Feinberg, Pedersen, Smith \& Vazquez-Nutall, 1982; Byram, 1997; Fantini, 2000; Ponterotto, Gretchen, Utsey, Rieger \& Austin, 2002; Pope, Reynolds, and Mueller, 2004). The Communication skills factor is the fifth and final factor. It consists of three elements, comprising a separate group in the five-factor solution. These are items aimed at estimating one's own skills related to communication with minorities. Communication skills become increasingly important in a situation when it is necessary for one of the communicating parties to communicate in a foreign (i.e. non-native) language, which is often the case when dealing with migration in Europe. The linguistic aspects of multicultural competence play an important role in Fantini's (2000) ICC model.

A rather small sample size $(n=363)$ was recognised as a limiting research factor. The research team realises the need for further research and testing of the functionality of the model. We propose the following in order to further test the five extracted factors: e.g. their reduction into four dimensions of multicultural competence: cognitive (the Knowledge factor and Understanding of terms), affective (the Awareness f.), behavioural (the Communication skills f.) and non-cognitive (the Activity f.).

\section{Conclusion}

The study focused on the development of self-assessment scale designed to measure the level of multicultural competence in students of helping professions, namely university students of pedagogical, social and healthcare fields who are more likely to encounter people of different cultures and nationalities in their future professions. To ensure that university preparation concerning multicultural education is the most effective, we need a tool to assess multicultural competence. For this purpose A Multicultural Competence Scale in Helping-Profession Students containing 20 self-report scales in five areas: Knowledge, Understanding of terms, Awareness, Communication Skills and Activity was created. 
We believe that it is important to subject the scale to further examination: in order to test its functionality in a larger sample and to subject it to a structural modelling with the aim to clarify the relationships among different areas. However our focus on a rather neglected group, namely university students of helping professions, is also regarded as significant. The research is thus closely linked with the process effectiveness of educational preparation.

\section{Acknowledgement}

The article was created within a grant project GA CR P407/12/P196 Development of Determinants of Multicultural Competence in Students of Helping Professions.

\section{References}

Albright, J. J., \& Park, H. M. (2009). Confirmatory factor analysis using Amos, LISREL, Mplus, and SAS/STAT CALIS. Working paper. The University Information Technology Services (UITS) Center for Statistical and Mathematical Computing, Indiana University. Retrieved from $\mathrm{http}: / /$ www.indiana.edu/ statmath/stat/all/cfa/index.html

Brown, T. A. (2006). Confirmatory factor analysis. New York: Guilford Press.

Byram, M. (1997). Teaching and assessing intercultural communicative competence. Clevedon: Multilingual Matters.

Byram, M., Nichols, A., \& Stevens, D. (Eds.). (2001). Developing intercultural competence in practice. Clevedon: Multilingual Matters.

Castelanos, J., Gloria, A. M., Mayorga, M., \& Salas, C. (2007). Student affairs professionals‘ self-report of multicultural competence: Understanding, awareness, knowledge, and skills. NASPA Journal, 44(4), 643-663.

Deardorff, D. K. (2006). Identification and assessment of intercultural competence as a student outcome of internationalization. Journal of Studies in International Education, 10(3), 241-266. http://dx.doi.org/10.1177/1028315306287002

Deardorff, D. K. (Ed.). (2009). The SAGE Handbook of intercultural competence. Thousand Oaks: SAGE Publications.

Fantini, A. E. (2000). A Central concern: Developing intercultural competence. SIT occasional papers series addressing intercultural education, training \& service. Retrieved from http://citeseerx.ist.psu.edu/viewdoc/download?doi=10.1.1.117.8512\&rep=rep1\&type=pdf\#page=33

Gamst, G., Dana, R. H., Der-Karabetian, A., Aragon, M., Arellano, L., Morrow, G., \& Martenson, L. (2004). Cultural competency revised: The California brief multicultural competence scale. Measurement and Evaluation in Counseling and Development, 37(3), 163-183.

Gamst, G. C., Linag, Ch. T. H., \& Der-Karabetian, A. (2011). Handbook of multicultural measures. Los Angeles: SAGE.

Harrington, D. (2009). Confirmatory factor analysis. New York: Oxfords Press.

Hladik, J. (2011). The Relationship of the cognitive and affective element of multicultural competences. Pedagogika, 51(1), 53-65.

Hladik, J., Hrbackova, K., \& Vavrova, S. (2012). Individual importance of multicultural competence in relation to components of students' self-regulated learning. Procedia Social and Behavioral Sciences, 69(24), 341-349. http://dx.doi.org/10.1016/j.sbspro.2012.11.419

Kaplan, D. (Ed.). (2004). The SAGE Handbook of quantitative methodology for the social sciences. Thousand Oaks: SAGE Publications.

Kim, B. S. K., Cartwright, B. Y., Asay, P. A., \& D'Andrea, M. J. (2003). A Revision of the multicultural awareness, knowledge, and skills survey-counselor edition. Measurement and Evaluation in Counseling and Development, 36(3), 161-180.

Lustig, M. W., \& Koester, J. (2010). Intercultural competence: Interpersonal communication across cultures. Boston: Allyn \& Bacon.

Ponterotto, J. G., Gretchen, D., Utsey, S. O., Rieger, B. P., \& Austin, R. (2002). A Revision of the multicultural counseling awareness scale. Journal of Multicultural Counseling and Development, 30(3), 153-180. http://dx.doi.org/10.1002/j.2161-1912.2002.tb00489.x 
Pope, R. L., \& Reynolds, A. L. (1997). Student affairs core competencies: Integrating multicultural awareness, knowledge, and skills. Journal of College Student Development, 38(3), 266-277.

Pope, R. L., \& Mueller, J. A. (2000). Development and initial validation of the multicultural competence in student affairs-preliminary 2 scale. Journal of College Student Development, 41(6), 599-608.

Pope, R. L., Reynolds, A. L., \& Mueller, J. A. (2004). Multicultural competence in student affairs. San Francisco: Jossey-Bass.

Rogers, M. R., \& Ponterotto, J. G. (1997). Development of the multicultural school psychology counseling scale. $\begin{array}{llll}\text { Psychology in the Schools, } & \text { 211-217. }\end{array}$ http://dx.doi.org/10.1002/(SICI)1520-6807(199707)34:3<211::AID-PITS3>3.0.CO;2-R

Sodowsky, G. R., Taffe, R. C., Gutkin, T. B., \& Wise, S. L. (1994). Development of the multicultural counseling inventory (MCI): A self-reported measure of multicultural competencies. Journal of Counseling Psychology, 41(2), 131-148. http://dx.doi.org/10.1037/0022-0167.41.2.137

Sue, D. W., Carter, R. T., Casas, J. M., Fouad, N. A., Ivey, M. J., Jensen, M., ... Vazquez-Nutall, E. (1998). Multicultural counseling competencies. Thousand Oaks: SAGE Publications.

Sue, D. W., Bernier, J. E., Durran, A., Feinberg, L., Pedersen, P., Smith, E. J., \& Vazquez-Nutall, E. (1982). Position paper: Cross-Cultural counseling competencies. The Counseling Psychologist, 42(10), 45-52. http://dx.doi.org/10.1177/0011000082102008

\section{Copyrights}

Copyright for this article is retained by the author(s), with first publication rights granted to the journal.

This is an open-access article distributed under the terms and conditions of the Creative Commons Attribution license (http://creativecommons.org/licenses/by/3.0/). 